\title{
Thrombotic Complications in Cirrhotic Patients: Balancing Risks and Benefits of Anticoagulation Treatment
}

\author{
Ecaterina Scãrlãtescu ${ }^{1}$, Mercedes S. Mandell ${ }^{2}$, Dana R. Tomescu ${ }^{1,3}$ \\ 'Department of Anesthesiology and Intensive Care III, Fundeni Clinical Institute, Bucharest, \\ Romania \\ 2Department of Anesthesiology, University of Colorado Health Sciences Center, Aurora, \\ Colorado, United States \\ 3University of Medicine and Pharmacy "Carol Davila", Bucharest, Romania
}

\author{
Corresponding author: \\ Dana R. Tomescu, MD, PhD \\ Associate Professor, \\ University of Medicine and Pharmacy \\ "Carol Davila", Bucharest, Romania \\ Head of Anesthesiology and Intensive \\ Care Department III, Fundeni Clinical \\ Institute, Fundeni no 258, 022328, \\ Bucharest, Romania \\ E-mail: danatomescu@gmail.com
}

\section{ABSTRACT}

The risk of excessive bleeding and thrombotic complications coexist in cirrhotic patients due to synthetic reduction in both pro and anticoagulants. However, investigators suggest the prevalence and consequences of thrombotic complications are underestimated. There is convincing evidence that thrombosis causes worsening portal hypertension, hepatic fibrosis and increases patient mortality. New evidence is emerging about the benefits of treating and preventing thrombotic complications in patients with liver disease. In the absence of welldesigned trials, clinical experience has become the most consistent guide to choose and dose anticoagulant drugs in this patient population. Practical use of anticoagulants however, is hindered by the lack of simple methods to monitor drug effect. In this review, we present a concise appraisal of current evidence on the most commonly studied indications for anticoagulation in cirrhotic patients. Information about drug action, dosing and monitoring are presented to provide a basis for clinical decision-making. The ongoing challenges in identifying therapeutic targets for treatment and monitoring drug effects are examined to highlight important clinical questions that have not yet been fully addressed.

Key words: liver cirrhosis; coagulation; bleeding; thrombosis

\section{INTRODUCTION}

Health care providers have primarily focused upon the prevention and treatment of bleeding episodes in cirrhotic patients (1). A lack of laboratory measures identifying thrombosis risk has given clinicians the impression that patients are "auto-anticoagulated" and at low risk of thromboembolic disease (2-4). Only recently have the importance of thrombosis in cirrhotic patients been recognized and investigators think the frequency and severity of the resulting complications are still underestimated (5).

Pro and anticoagulant factors play a critical role in forming mechanically effective clot that is limited to the site of injury $(2,6)$. The same balance is 
present in patients with compensated liver disease. However, coagulation is "rebalanced" by an equal reduction in factors that build and prevent clotting. Physiological insults such as sepsis or kidney dysfunction easily tip this new and fragile balance to cause bleeding and/ or thrombotic complications.

New clinical findings show that thrombosis can cause acute hepatic decompensation, disease progression and death in cirrhotic patients (7-9). While treatment with anticoagulants reduces morbidity and mortality associated with thrombotic complications in a number of diseases, the data about risks and benefits of anticoagulation in cirrhotic patients is only beginning to accrue. Durable recommendations about indications, dosing and therapeutic safety indices still require more information from well-designed studies.

The aim of this review is to provide a concise yet comprehensive appraisal of current research that outlines the risks and benefits of anticoagulation in cirrhotic patients. We limited our review to the most studied indications for anticoagulation in cirrhotic patients. A summary of up to date information about the pharmacology and monitoring of anticoagulants is provided to assist care providers in clinical decision making. We use the evidentiary base to identify gaps in knowledge that require future work to improve patient outcomes.

\section{MOST COMMONLY STUDIED INDICATIONS FOR ANTICOAGULATION IN CIRRHOTIC PATIENTS}

\section{Portal vein thrombosis (PVT)}

The prevalence of nonmalignant PVT in cirrhosis is estimated at $10-25 \%$ (10). Acute PVT can abruptly increase portal hypertension leading to decompensation and death. Further, transplantation may not be possible if clot propagates into the mesenteric veins. Risk factors for PVT are unknown, but variceal bleeding, low platelet count and reduced portal flow velocity are associated findings $(4,11)$.

Population studies suggest thrombophilic factors occur in up to $39 \%$ of patients with PVT (12). The most common were Factor $V$ Leiden, prothrombin 20210A mutation and Plasminogen activator inhibitor 4G-4G. The prevalence of thrombophilia in PVT may be underestimated as standard coagulation profiles often fail to identify increased clotting and routine screening for thrombophilic factors is rarely performed (12-14).

Differences in opinion about anticoagulation for PVT stem from findings showing that nearly half of affected patients experience some degree of spontaneous recanalization (15). However, a systematic review showed a pooled Odds Ratio of $4.16(95 \% \mathrm{Cl}=1.88-$ $9.20, \mathrm{P}=0.0004)$ for complete recanalization in treated compared to untreated patients (16). Findings from the same systematic review showed that bleeding complications were rare and patient death was not due to treatment (16).

The findings show anticoagulation increases portal vein patency and reduces complications due to PVT. Observations from a small randomized controlled trial in advanced and compensated cirrhosis also suggest the benefits of routine PVT prophylaxis outweigh the risks (17). The findings are promising, but more outcome data is needed to construct a robust therapeutic safety index capable of guiding treatment. Regardless of these limitations, many investigators consider current findings convincing enough to recommend anti-coagulation for treatment and prophylaxis of PVT (17).

\section{Budd-Chiari syndrome (BCS)}

Obstruction of outflow between the small hepatic veins and the inferior vena up to the level of the right atrium is rare in Western countries and usually due to multiple thrombophilic disorders including myeloproliferative disease (18). Congenital endoluminal abnormalities explain the higher prevalence in Asian countries (19). Therapeutic options include anticoagulation, recanalization, surgical shunting, transjugular intrahepatic portosystemic shunting and transplantation. Anticoagulation is a common initial intervention (20). The strategy for anticoagulation is extrapolated from outcomes in patients with venous thromboembolism (VTE) due to thrombophilic disorders. However, anticoagulation as a single therapy is only effective in $10 \%$ of BCS cases (21).

\section{Venous thromboembolism (VTE)}

The reported incidence of deep vein thrombosis and pulmonary embolism in hospitalized patients with chronic liver disease varies from 0.5 to $6.3 \%(4,22)$. Incidence increased with severity of illness measured by Child-Pugh (22). Age less than 45 years increased the risk in compensated (OR $1.23 ; 95 \% \mathrm{Cl} 1.04$ to 1.46) and decompensated patients (OR 1.39; $95 \% \mathrm{Cl} 1.15$ to 1.69)(23).

Investigators suggest VTE is still underestimated because routine screening is rarely performed and standard coagulation tests are not diagnostic (2-4). Patients at increased risk include those with Hepatitis A, $B$ and $C$ in addition to Epstein Barr and Cytomegalovirus (24). Investigators theorize that viral-induced inflamma- 
tion activates coagulation factors, downregulates anticoagulants and inhibits fibrinolysis (25).

A pulmonary embolus mortality risk of $35 \%$ compared to $16 \%$ in noncirrhotic patients and longer hospital stay supports routine surveillance and anticoagulation for VTE in hospitalized cirrhotic patients (26). Few adverse outcomes in patients with decompensated cirrhosis treated for PVT suggest there could be a similar risk-benefit profile for treatment of VTE. To date, prophylaxis for VTE requires additional evaluation (2).

\section{Thrombosis-associated hepatic fibrosis}

Human and experimental animal evidence link hepatic microvascular thrombosis with tissue parenchyma fibrosis (26). A similar relationship between microvascular clotting and fibrosis has been reported in progressive lung and kidney diseases and suggests that in situ small vessel thrombosis may be a common end pathway for a number of pathological conditions $(24,25)$. Recent studies show microvascular thrombosis initiates inflammation and stellate cell activation, two molecular pathways associated with increased thrombin generation and fibrin formation $(26,27)$. Theories implicating parenchyma extinction also identify microvascular thrombosis as the first step in a cascade leading to fibrosis (27).

Hepatic fibrosis progresses faster in patients with genetic mutations for Factor $\mathrm{V}$ Leiden, protein $\mathrm{C}$ deficiency or increased expression of factor VIII than in patients with hemophilia and Hepatitis $C(5,28)$. The fibrotic response is slower in experimental animals with inhibition of endothelial-based Tissue Factor and P-selectin $(29,30)$. Evidence suggests multiple sites in the coagulation cascade initiate inflammation which stimulates the synthesis of interstitial molecules (31).
The current evidence specifically implicates increased clot formation as a cause of progressive fibrosis but, it is unknown if anticoagulation will mitigate this response. The evidence is very compelling and clinical trials are the next logical step.

\section{Use of extracorporeal circuits for life support}

Extracorporeal circuits are often used in cirrhotics without anticoagulation due to concerns about heparininduced bleeding risk. Clot accumulation in extracorporeal circuits is common in cirrhotic patients compared to patients with other causes of renal failure (32). Heparin administration however, failed to increase circuit patency times and was associated with increased bleeding complications (33). Other anticoagulants used to promote extracorporeal circuit patency did not perform better than heparin $(34,35)$. Citrate anticoagulation can safely be used in liver transplant patients, but the filter running time was still limited to approximately 23 hours (35). There is general agreement that the risk of heparinization exceeds the benefit in renal replacement circuits (33).

\section{PHARMACOLOGY AND MONITORING OF ANTICOAGULANT DRUG}

Choice of anticoagulant drugs for clinical use in cirrhotic patients is complicated by a lack of welldesigned efficacy and safety trials. Current studies in cirrhotic patients have not tested for differences in response due to factors such as demographic heterogeneity, severity of illness and etiology of disease. Therefore clinicians often draw from their knowledge about the pharmacological behavior of anticoagulant drugs (fig. 1).

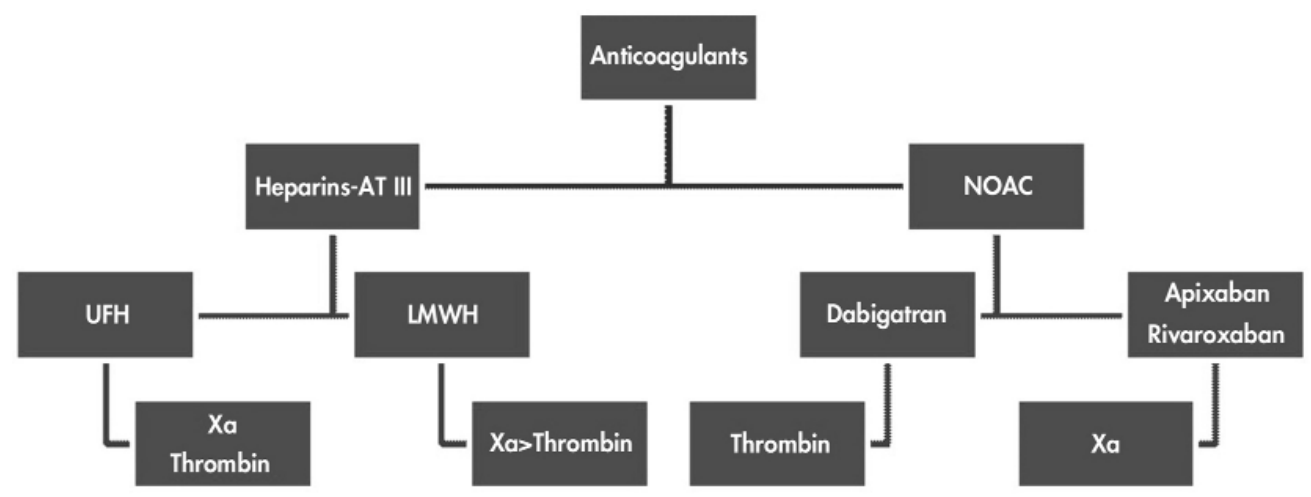

Figure 1 - Two major classes of anticoagulant drugs are the Heparins and Novel Oral Anticoagulants (NOAC). Unfiltered heparins are larger than Low Molecular Weight Heparin (LMWH). Both groups of heparin-based drugs are activated by binding Antithrombin III (AT III). AT-III activated LMWH have higher affinity for factor Xa than for thrombin. NOAC bind and inactivate either thrombin or factor Xa 


\section{Heparin: unfractioned heparin and low molecular weight heparin}

\section{Pharmacology}

Unfractionated heparin (UFH) is a naturally occurring molecule bound to endothelial cells. Molecules are repeating disaccharide units that vary between 3000 to 30,000 Daltons (36). When given parenterally, UFH, binds Antithrombin III (AT III), inducing conformational changes that causes the UFH-AT-III complex to bind and inactivate thrombin and factor Xa (36). Smaller UFH segments complex with AT IIII and inactivate factor Xa, while longer segments are required to inhibit thrombin (37). Duration of action is one to two hours (table 1).

Low molecular weight heparins (LMWH) are formed by chemical or enzymatic breakdown of large UFH molecular fragments to yield smaller subunits. Purity assays require at least $60 \%$ of heparin chains are 8000 Daltons or less (37). LMWH form a complex with AT III to primarily inhibit factor $X a$. The preferential inhibition of factor Xa produces more predictable anticoagulant effects than unfractionated heparins.

\section{Duration of action}

Steady state drug levels for UFH require 6 hours compared to approximately two to four days for LMWH. The elimination half-life of UFH is $60-150$ minutes compared to 4.5 hours for LMWH (33). Heparin half-life is determined by the rate of cellular uptake, renal excretion and binding to Antithrombin III. Human hyaluronic acid receptors for endocytosis (HARE)/ stabilin-2 in liver sinusoidal endothelial cells clear UHF and LMWH (38). Affinity for HARE is higher for UFH than LMWH but uptake for both is facilitated by AT III binding. Renal excretion becomes the primary route of elimination when cellular uptake is saturated (39). In contrast, LMWH is eliminated by the kidneys only after hepatic partial depolymerization and/or desulfation (40). Therefore renal elimination becomes the primary determinant of half-life during continuous treatment (39).

\section{Monitoring heparin-anticoagulation in cirrhosis}

The activated partial prothrombin time (aPTT) is a standard measure of UFH anticoagulant effect, but poorly predicts coagulation inhibition in cirrhosis (41, 42). Baseline aPTT values often exceed normal limits in most cirrhotic patients because the assay only measures procoagulant activity which is reduced due to synthetic failure.

The aPTT does not measure anticoagulant activity and can overestimate bleeding risk, leading to subtherapeutic dosing. To date there are no evidencebased algorithms to guide UFH dosing that considers the balance between procoagulant and anticoagulant factors. Even tests that use a direct measure of thrombin activity have poor predictability $(43,44)$.

Monitoring is rarely performed in non-cirrhotic patients taking LMWH due to the relatively large therapeutic safety index. When required, the anti-Xa assay is used to determine therapeutic effect $(45,46)$. The assay is performed by adding patient plasma to a known excess of factor Xa and AT III. The amount of remaining $\mathrm{Xa}$ is used to extrapolate the degree of coagulation inhibition $(46,47)$.

Results of the anti-Xa assay can be unreliable due to inconsistent sources of commercially available antifactor Xa substrates and the use of blood samples outside peak activity. Further, the test presumes patients

Table 1 - Pharmacokinetic and pharmacodynamic properties of Unfractionated Heparin (UFH) and Low Molecular Weight Heparins (LMWH)

\begin{tabular}{|c|c|c|}
\hline Property & Unfractionated Heparin & Low Molecular Weight Heparin \\
\hline Chemical Composition & $\begin{array}{l}\text { Polysaccharide with repeating } \\
\text { disaccharide units }\end{array}$ & Same but less heterogeneous \\
\hline Molecular Weight & $3000-30,000$ Daltons & $4,000-6,000$ Daltons \\
\hline Administration & Parenteral & Parenteral \\
\hline Inhibitory activity & Primarily Thrombin & Primarily Xa \\
\hline Elimination half-life & 1.5 hours $(1-2)$ & 4.5 hours $(4-6)$ \\
\hline Metabolism & Hepatic (HARE receptors) & $\begin{array}{l}\text { Hepatic } \\
\text { (HARE receptors and desulfation or depolymerization) }\end{array}$ \\
\hline Elimination & Renal-dose dependent & Renal-dose independent \\
\hline Standard Laboratory Monitoring & $\mathrm{aPTT}$ & Antifactor Xa and thrombin generation \\
\hline Reversal & Protamine & Partially reversed by Protamine \\
\hline
\end{tabular}

Abbreviations: Activated Partial Thromboplastin Time (aPTT), Hyaluronic acid receptors for endocytosis (HARE) 
have normal AT III levels (41). Most cirrhotic patients develop profound AT III deficiency ( $<30 \%$ activity) due to hepatic synthetic failure. Therefore, the accuracy of the assay declines as the severity of cirrhosis increases (42).

Thrombin generation tests also estimate LMWH anticoagulant effect. The degree of coagulation inhibition measured by the anti-Xa and thrombin generation tests vary and make clinical interpretation difficult (48). Similar discordant findings are also reported in pregnant patients (49). Thrombin generation tests for monitoring are now commonly used as opposed to anti-Xa since the former provides a more detailed pharmokinetic profile.

\section{Newer low molecular weight heparins}

Newer LMWH have a narrower range of mean molecular weights that make the duration of action more predictable (50). The ratio of anti-Xa and antithrombin activity varies for each LMWH. Smaller LMWH drugs such as Bemiparin (3,600 D) have the highest anti-Xa to anti-thrombin activity. The relative proportion of anti-thrombin activity increases with molecular weight, explaining why Tinzaparin $(6,500 \mathrm{D})$ has the lowest anti-Xa to anti-thrombin activity. For example, Tinzaparin has much higher dose dependent anti-thrombin activity compared to Enoxaparin $(4,400$ D) (50).

Lower molecular weight is associated with accumulation in renal disease. Tinzaparin has the highest molecular weight of all marketed LMWH and is least dependent upon renal excretion (38). Studies in elderly patients showed less accumulation of Tinzaparin compared to Enoxaparin with a creatinine clearance $<20 \mathrm{~mL} / \mathrm{min}(51)$.

\section{New oral anticoagulants (NOAC)}

\section{Pharmacology}

New oral anticoagulants are molecular heterogeneous drugs that bind and inactivate thrombin or $\mathrm{Xa}$ (table 2). Dabigatran was the first NOAC released for use. It directly inhibits thrombin, while Endoxaban, Rivaroxaban and Apixaban inhibit free factor Xa and Xa bound to prothrombinase complex (52). The thrombin inhibitor, Dabigatran has a larger anticoagulant effect in cirrhotic versus control patients compared to the direct factor Xa inhibitors, Rivaroxaban and Apixaban which were less potent than in control patients (43).

Advantages of NOAC include oral administration, no requirement for bridging therapy, few drug restrictions, reversal with recombinant prothrombin complexes or specific agents like Idarucizumab for Dabigatran reversal (53) and no need for monitoring in most patient populations (54). Oral administration is particularly advantageous in cirrhotic patients who require long term anticoagulant administration $(2,55)$.

\section{Duration of action}

The half-life of NOAC vary between 5 and 17 hours (table 2). The shorter half-life of the factor Xa inhibitor, Rivaroxaban (5-9 hours) improves safety. Up to $33 \%$ of the drug is eliminated unchanged by the kidney while $66 \%$ is metabolized by the liver before renal elimination. In contrast Dabigatran must be activated by hepatic metabolism (54). The half-life is considerably longer (12-17 hours) than Rivaroxaban, but the mean plasma terminal half-life is independent of dose which improves the ability to predict duration of action. Apixaban is another factor Xa inhibitor with a half-life

Table 2 - A summary of pharmacokinetic and pharmacodynamic information on Novel Oral

\begin{tabular}{|c|c|c|c|}
\hline NOAC & Dabigatran & Rivaroxaban & Apixaban \\
\hline Trade name & Pradaxa, Praxaza, Pradax & Xarelto & Eliquis \\
\hline Site of Action & thrombin & $\mathrm{Xa}$ & $\mathrm{Xa}$ \\
\hline Bioavailability & $3-7 \%$ & $80-100 \%$ & $50 \%$ \\
\hline Metabolism & Hepatic glucuronidation & $\begin{array}{l}\text { Hepatic metabolism (66\%) CYP3A4, } \\
\text { CYP2J2 and CYP-independent mechanisms }\end{array}$ & $\begin{array}{l}\text { Hepatic } \\
\text { CYP3A4, CYP3A5, CYP1A2 }\end{array}$ \\
\hline Half-life & $12-17$ hours & $5-9$ hours & $9-14$ hours \\
\hline Elimination & $\begin{array}{l}\text { Renal } 7 \% \\
\text { GI } 87 \%\end{array}$ & $\begin{array}{l}\text { Renal } \\
\text { Metabolized }(66 \%) \\
\text { Unchanged }(33 \%)\end{array}$ & $\begin{array}{l}\text { Biliary }(75 \%) \\
\text { Renal }(25 \%)\end{array}$ \\
\hline Monitor: None & TCT-based tests & $\begin{array}{l}\text { Modified chromogenic } \\
\text { Anti-Xa assay }\end{array}$ & $\begin{array}{l}\text { Modified chromogenic } \\
\text { Anti-Xa assay }\end{array}$ \\
\hline Reversal & $\begin{array}{l}3 \text { and } 4 \text { PTC } \\
\text { Idarucizumab }\end{array}$ & $\begin{array}{l}3 \text { and } 4 \text { PTC } \\
\text { Reversal agents in development }\end{array}$ & $\begin{array}{l}3 \text { and } 4 \text { PTC } \\
\text { Reversal agents in development }\end{array}$ \\
\hline
\end{tabular}

Abbreviations: Anticoagulant Drugs (NOAC). Cytochrome P (CYP), Gastrointestinal (Gl), Prothrombin Complex (PTC), Thrombin Clotting Time (TCT) 
of 8-15 hours. However, it has the smallest renal clearance of all NOAC drugs (25\%). Apixaban and Rivaroxaban are metabolized in the liver by the Cytochrome P450-dependent isozyme pathway prior to elimination (54).

\section{Monitoring}

There are no laboratory assays capable of measuring NOAC anticoagulation effect (55). Dilute thrombin generation time, Ecarin clotting and chromogenic assays correlate best with drug concentration, but are not approved by U.S. regulatory agencies for testing (56). In addition, dosing adjustments for age or renal and hepatic disease have not been developed (57).

The Prothrombin Time and Ecarin venom test can be used to estimate clotting inhibition but are unreliable due to differences in thromboplastin assay agents (58). The diluted thrombin time and Ecarin clotting times only estimate plasma drug concentration (59). Therapeutic ranges are unknown and concentration does not reliably predict activity (56). The results from in vitro studies found chromogenic anti-Xa assays may be better estimates of direct $X a$ inhibitors even though this test underestimates AT III-dependent drug levels in cirrhotic patients (42).

\section{CLINICAL EXPERIENCE WITH ANTICOAGULATION IN CIRRHOSIS}

\section{Experience with PVT}

There is growing support for routine use of anticoagulation in all cirrhotics with newly diagnosed nonmalignant PVT. Most clinical experience is derived from studies using the LMWH, Enoxaparin. Most patients had partial or complete resolution of PVT following treatment over 7-17 months (60-62). However, limited data suggests at least 39\% recurrence after treatment was stopped.

The natural history of PVT is similar to spontaneous pulmonary embolism where therapeutic benefit is lost after discontinuing treatment (63). This raises questions about treatment strategies and if long term post thrombotic prophylaxis is of benefit. At least one study showed de novo PVT could be prevented by prophylactic treatment. While it is reasonable to speculate that prophylaxis could reduce the risk of recurrent PVT, this assumption requires confirmatory evidence (17).

There is limited experience with newer anticoagulant drugs for PVT or other thrombotic complications of cirrhosis. Anticoagulant drugs are not necessarily interchangeable even if they belong to the same family of medications. A comparison of half-life, duration of action and type of elimination within each drug group indicates that each drug has a unique pharmacological profile.

Clinical experience with NOAC in PVT is limited to small studies and case reports as cirrhotic patients were excluded from commercially sponsored Phase III trials. Use of these products in cirrhotics is considered offlabel. Successful treatment of PVT with or without mesenteric extension of clot was reported in a series of 5 patients and in a separate single case report $(64,65)$. All patients were Child A, without varices. Resolution of PVT required six months of therapy. No major bleeding complications were reported (66). Mild hepatic impairment did not seem to alter the pharmacokinetics of Rivaroxaban. However, moderate hepatic impairment significantly increased plasma levels (67).

The decision to treat PVT with anticoagulants appears evidence based and has a sound line of scientific reasoning (68). However, some investigators argue PVT is probably a distant marker of worse patient survival regardless of successful recanalization and the important benchmark is a critical reduction in portal venous velocity that precedes in situ thrombosis (69). This difference in viewpoints has made it difficult to find consensus on anticoagulant management of PVT (60).

\section{Experience with BCS}

Investigators suggest limiting anticoagulation for BSC to patients without portal hypertension to reduce risk of bleeding complications and because of a poor long term response rate (70). Heparins (UFH and LMWH) appear to have equal efficacy to Vitamin $\mathrm{K}$ antagonists (71). However, Vitamin $\mathrm{K}$ antagonists are often preferred due to ease of long term oral administration. There is limited evidence for choice of anticoagulants following percutaneous or surgical recanalization and transplantation. A retrospective single center study of balloon dilation reported complete clot resolution in 12 of 19 and partial resolution in the remaining 7 BCS patients at $15.9 \pm 14.4$ months using Warfarin (72). The antithrombotic effects of aspirin were equally effective as Vitamin K Antagonists in patients with thrombophilia due to myeloproliferative disorders well controlled on hydroxyurea (73). To date there are no studies using newer LMWH or NOAC in BCS.

\section{Experience with VTE}

Evidence suggests VTE prophylaxis improves patient survival and reduces length of hospitalization in cirrhotic patients. Early studies found prophylaxis with LMWH or UFH failed to prevent VTE and increased bleeding complications $(44,74)$. A reduction in VTE rate however, was reported in a larger study cohort 
comprised of younger hospitalized cirrhotics. The diagnostic rate was greater in the younger cohort $(1.5 \%$ vs. $0.5 \%)(75)$. The findings are consistent with previous observations showing a relationship between younger age in cirrhotics and risk of VTE (23). Older age in earlier studies also probably explains the higher number of bleeding episodes $(76,77)$.

\section{Experience with hepatic fibrosis}

There is strong experimental data supporting observations that in situ thrombosis increases the risk of progressive fibrosis. However, there are no corresponding human trials. Select anticoagulants may have additional properties that modulate ischemia and the fibrotic response. Rats treated with Enoxaparin and Nadroparin had significantly less hepatic fibrosis compared to those treated with Tinzaparin (78). A link between Rivaroxaban and inhibition of inflammatory pathways was found in models of ischemic stroke. Better outcome in Rivaroxaban treated rats was related to down regulation ICAM- 1 expression and the activation of CD68+-immune cells in addition to thrombin inhibition (79).

\section{Vitamin $K$ antagonists (VKA)}

Vitamin $\mathrm{K}$ antagonists still form a mainstay of therapeutic intervention at many institutions. Warfarin binds and inactivates Vitamin $\mathrm{K}$ epoxide reductase, the enzyme that returns Vitamin $\mathrm{K} 1$ to an active form. This depletes Vitamin $\mathrm{K} 1$, the substrate needed to activate coagulation proteins (II, VII, IX, X, protein C, and S). Onset of action is delayed for two to three days until there is natural attrition of activated coagulation proteins. Protein $\mathrm{C}$ and $\mathrm{S}$ levels drop faster than procoagulant factors leaves a vulnerable period where the risk of thrombosis is theoretically increased. Short acting anticoagulants with rapid onset are therefore often used to initiate anticoagulation during treatment with VKA. Treatment requires regular monitoring. The most common monitoring test is the International Normalized Ratio (INR).

\section{Monitoring}

The therapeutic target for INR in cirrhotic patients is often unclear due to prolongation of the INR caused by reduced procoagulant synthesis (2). A comparison of assays including INR shows thrombin generation captures more detailed information about the global coagulation cascade. However, there was a large variation across a narrow range of INR values even in thrombin generation testing (80).

\section{Shortfalls in clinical monitoring}

The prothrombin time was previously used to measure therapeutic effect in patients taking VKA. Different sourcing of assay thromboplastin substrates gave rise to variable test results. The World Health Organization endorsed use of a normalized value based upon a single thromboplastin source (81). The resulting international sensitivity index (ISI) corrects prothrombin times into values that can be compared over time and between institutions $(81,82)$. The resulting INR values can only be used in patients without pre-existing coagulation defects and there is no simple approach to normalize the INR in cirrhosis (82).

Investigators suggested using plasma from healthy and cirrhotic patients to normalize the INR (82). Each thromboplastin would have 2 ISI values: one for patients on VKA and one for cirrhotic patients. This should reduce inter-laboratory variability for INR values. However, it is unlikely that a single ISI for liver would work equally well in all cirrhotic patients due to differences in coagulation profiles caused by severity of illness. The other remaining alternative is to measure factor levels (2).

\section{Clinical outcomes}

There are no large randomized trials and most evidence supporting use of VKA in cirrhotic patients comes from small single center reports. Treatment appears to improve PVT with and without thrombophilia (83). Few bleeding complications have been reported following PVT treatment with either VKA or LMWH (84, 85). Similar findings were reported in a single center study of VKA thrombosis prophylaxis in liver transplant recipients (86). Patients with splanchnic thrombosis have been safely treated with VKA after initiation treatment with LMWH. Patients in this study had an average MELD score of 13 and the INR was kept between values of 2-3 during treatment (87).

A single study found cirrhotic patients with atrial fibrillation experienced more bleeding complications when treated with VKA (88). Bleeding complications were mostly due to varices and hemorrhagic stroke. However, a higher prevalence of neurological vascular accident and hypertension in this population prior to VKA treatment may explain these findings. Endoscopic treatment of varices was not reported. Further, the only test that guided VKA administration was the INR and end points for treatment were unclear. The authors still concluded however, that the risk compared to benefit of VKA use seemed favorable for patients with earlier stages of cirrhosis $(88,89)$. 


\section{CONCLUSIONS}

A focus upon the most commonly studied indications for anticoagulation in cirrhotic patients allowed us to compile enough evidence to uncover trends in anticoagulant treatment and identify knowledge gaps that cause uncertainty in clinical decision making. We found general agreement that treatment of thrombosis in cirrhosis reduces morbidity and mortality. The strongest evidence came from studies of PVT.

Evidence outlining the risks and benefits of PVT prophylaxis were more controversial. However, the findings were encouraging and can be considered a launch point for future investigation. Larger and better designed studies are needed to confirm observations about the benefits of anticoagulation prophylaxis and treatment for PVT and VTE. The ability of some anticoagulant drugs to modulate the fibrotic response in experimental animals is an exciting finding that still needs translation into human studies.

There are few reliable tests to monitor anticoagulant activity in cirrhotic patients and standard tests have inherent faults that limit clinical use. The desire to monitor anticoagulant effects is driven by the lack of steady state in coagulation synthesis and drug metabolism and elimination. Developing reliable and validated tests for measuring coagulation profiles and therapeutic effect will be one of the most important pieces of the puzzle for developing a rational approach to anticoagulation in cirrhosis.

\section{REFERENCES}

1. Caldwell S, Intagliata N. Dismantling the myth of "autoanticoagulation in cirrhosis: an old dogma dies hard. Hepatology. 2012 May;55(5): 1634-7.

2. Lisman T1, Kamphuisen PW, Northup PG, Porte RJ. Established and new-generation antithrombotic drugs in patients with cirrhosis possibilities and caveats. J Hepatol. 2013 Aug;59(2):358-66.

3. Senzolo M, Sartori MT, Lisman T. Should we give thromboprophylaxis to patients with liver cirrhosis and coagulopathy? HPB (Oxford). 2009 Sep;11(6):459-64

4. Hugenholtz GC, Northup PG, Porte RJ, Lisman T. Is there a rationale for treatment of chronic liver disease with antithrombotic therapy? Blood Rev. 2015 Mar;29(2):127-36.

5. Tripodi A, Anstee QM, Sogaard KK, Primignani M, Valla DC Hypercoagulability in cirrhosis: causes and consequences. J Thromb Haemost. 2011 Sep;9(9):1713-23

6. Saner FH, Gieseler RK, AkIz H, Canbay A, Görlinger K Delicate balance of bleeding and thrombosis in end-stage liver disease and liver transplantation. Digestion. 2013:88(3):135-44.

7. Lisman T, Leebeek FW. Hemostatic alterations in liver disease: a review on pathophysiology, clinical consequences, and treatment. Dig Surg. 2007;24(4):250-8. Epub 2007 Jul 27.

8. Tripodi A, Salerno F, Chantarangkul V, Clerici M, Cazzaniga M, Primignani $\mathrm{M}$, et al. Evidence of normal thrombin generation in cirrhosis despite abnormal conventional coagulation tests. Hepatology. 2005 Mar;41(3):553-8.

9. Gatt A, Riddell A, Calvaruso V, Tuddenham EG, Makris M, Burroughs
AK. Enhanced thrombin generation in patients with cirrhosis-induced coagulopathy. J Thromb Haemost. 2010 Sep;8(9):1994-2000.

10. Tsochatzis EA, Senzolo M, Germani G, Gatt A, Burroughs AK. Systematic review: portal vein thrombosis in cirrhosis. Aliment Pharmacol Ther. 2010 Feb 1;31(3):366-74.

11. Rodriguez-Castro KI, Simioni P, Burra P, Senzolo M. Anticoagulation for the treatment of thrombotic complications in patients with cirrhosis. Liver Int. 2012 Nov;32(10):1465-76

12. D'Amico M, Pasta F, Pasta L. Thrombophilic genetic factors PAI-1 4G4G and MTHFR 677TT as risk factors of alcohol, cryptogenic liver cirrhosis and portal vein thrombosis, in a Caucasian population. Gene. 2015 Aug 15;568(1):85-8.

13. Chen H, Qi X, He C, Yin Z, Fan D, Han G. Coagulation imbalance may not contribute to the development of portal vein thrombosis in patients with cirrhosis. Thromb Res. 2013 Feb;131(2):173-7.

14. Rossetto V, Spiezia L, Senzolo M, Rodriguez-Castro KI, Maggiolo S, Simioni P. Whole blood rotation thromboelastometry (ROTEM(R)) profiles in subjects with non-neoplastic portal vein thrombosis. Thromb Res. 2013 Aug;132(2):e131-4.

15. Sogaard KK, Astrup LB, Vilstrup H, et al. Portal vein thrombosis; risk factors, clinical presentation and treatment. BMC Gastroenterology. 2007; 7(1):1-6

16. Qi X, De Stefano V, Li H, Dai J, Guo X, Fan D. Anticoagulation for the treatment of portal vein thrombosis in liver cirrhosis: a systematic review and meta-analysis of observational studies. Eur $\mathrm{J}$ Intern Med. 2015 Jan;26(1):23-9.

17. Villa $\mathrm{E}$, Cammà $\mathrm{C}$, Marietta $\mathrm{M}$, Luongo $\mathrm{M}$, Critelli $\mathrm{R}$, Colopi $\mathrm{S}$, et al. Enoxaparin prevents portal vein thrombosis and liver decompensation in patients with advanced cirrhosis. Gastroenterology. 2012 Nov; 143(5):1253-60.e1-4.

18. Martens P, Nevens F. Budd-Chiari syndrome. United European Gastroenterol J. 2015 Dec;3(6):489-500.

19. Darwish Murad S, Plessier A, Hernandez-Guerra M, Fabris F, Eapen $\mathrm{CE}$, Bahr MJ, et al. Etiology, management, and outcome of the BuddChiari syndrome. Ann Intern Med. 2009 Aug 4:151(3):167-75.

20. Seijo S, Plessier A, Hoekstra J, Dell'era A, Mandair D, Rifai K, et al. Good long-term outcome of Budd-Chiari syndrome with a step-wise management. Hepatology. 2013 May;57(5):1962-8.

21. Plessier A, Sibert A, Consigny $\mathrm{Y}$, Hakime A, Zappa M, Denninger MH, et al. Aiming at minimal invasiveness as a therapeutic strategy for Budd-Chiari syndrome. Hepatology. 2006 Nov;44(5):1308-16.

22. Dabbagh 0, Oza A, Prakash S, Sunna R, Saettele TM. Coagulopathy does not protect against venous thromboembolism in hospitalized patients with chronic liver disease. Chest. 2010 May:137(5):1145-9.

23. Pincus KJ, Tata AL, Watson K. Risk of venous thromboembolism in patients with chronic liver disease and the utility of venous thromboembolism prophylaxis. Ann Pharmacother. 2012 Jun;46(6):873-8.

24. Crooks MG. Hart SP. Coagulation and anticoagulation in idiopathic pulmonary fibrosis. Eur Respir Rev. 2015 Sep;24(137):392-9.

25. Tian S, Chen SY. Macrophage polarization in kidney diseases. Macrophage (Houst). 2015;2(1). pii: e679.

26. Anstee QM, Goldin RD, Wright M, Martinelli A, Cox R, Thursz MR. Coagulation status modulates murine hepatic fibrogenesis: implications for the development of novel therapies. J Thromb Haemost. 2008 Aug;6(8):1336-43.

27. Anstee QM, Dhar A, Thursz MR. The role of hypercoagulability in liver fibrogenesis. Clin Res Hepatol Gastroenterol. 2011 Sep;35(8-9):52633.

28. Yee $\Pi$, Griffioen A, Sabin CA, Dusheiko G, Lee CA. The natural history of HCV in a cohort of haemophilic patients infected between 1961 and 1985. Gut. 2000 Dec:47(6):845-51.

29. Rautou PE, Tatsumi K, Antoniak S, Owens AP 3rd, Sparkenbaugh E, Holle $L A$, et al. Hepatocyte tissue factor contributes to the hypercoagulable state in a mouse model of chronic liver injury. J Hepatol. 2016 Jan;64(1):53-9.

30. Diaz JA, Wrobleski SK, Alvarado CM, Hawley AE, Doornbos NK, Lester $\mathrm{PA}$, et al. P-selectin inhibition therapeutically promotes thrombus resolution and prevents vein wall fibrosis better than enoxaparin and an inhibitor to von Willebrand factor. Arterioscler Thromb Vasc Biol. 2015 Apr:35(4):829-37.

31. Levi M, Keller TT, van Gorp E, ten Cate H. Infection and inflammation 
and the coagulation system. Cardiovasc Res. 2003 Oct 15;60(1):2639.

32. Agarwal B, Shaw S, Shankar Hari M, Burroughs AK, Davenport A Continuous renal replacement therapy (CRRT) in patients with liver disease: is circuit life different? J Hepatol. 2009 Sep;51(3):504-9.

33. Chua HR, Baldwin I, Bailey M, Subramaniam A, Bellomo R. Circuit lifespan during continuous renal replacement therapy for combined liver and kidney failure. J Crit Care. 2012 Dec;27(6):744.e7-15.

34. Goonasekera CD, Wang J, Bunchman TE, Deep A. Factors affecting circuit life during continuous renal replacement therapy in children with liver failure. Ther Apher Dial. 2015 Feb;19(1):16-22.

35. Saner FH, Treckmann JW, Geis A, Lösch C, Witzke 0, Canbay A, et al. Efficacy and safety of regional citrate anticoagulation in liver transplant patients requiring post-operative renal replacement therapy. Nephrol Dial Transplant. 2012 Apr;27(4):1651-7.

36. Hirsh J, Anand SS, Halperin JL, Fuster V. Mechanism of action and pharmacology of unfractionated heparin. Arterioscler Thromb Vasc Biol. 2001 Jul;21(7):1094-6.

37. Hirsh J, Warkentin TE, Shaughnessy SG, Anand SS, Halperin JL, Raschke R, et al. Heparin and low-molecular-weight heparin: mechanisms of action, pharmacokinetics, dosing, monitoring, efficacy, and safety. Chest. 2001 Jan;119(1 Suppl):64S-94S

38. Harris EN, Baggenstoss BA, Weigel PH. Rat and human HARE/stabilin2 are clearance receptors for high- and low-molecular-weight heparins. Am J Physiol Gastrointest Liver Physiol. 2009 Jun;296(6): G1191-9.

39. Johansen KB, Balchen T. Tinzaparin and other low-molecular-weight heparins: what is the evidence for differential dependence on renal clearance? Exp Hematol Oncol. 2013 Aug 8;2:21.

40. Hoy SM, Scott LJ, Plosker GL. Tinzaparin sodium: a review of its use in the prevention and treatment of deep vein thrombosis and pulmonary embolism, and in the prevention of clotting in the extracorporeal circuit during haemodialysis. Drugs. 2010 Jul 9;70(10): 1319-47.

41. Potze W, Adelmeijer J, Porte RJ, Lisman T. Preserved clot formation detected by the Thrombodynamics analyzer in patients with cirrhosis. Thromb Res. 2015 May;135(5):1012-6.

42. Potze W, Arshad F, Adelmeijer J, Blokzijl H, van den Berg AP, Porte RJ, et al. Routine coagulation assays underestimate levels of antithrombindependent drugs but not of direct anticoagulant drugs in plasma from patients with cirrhosis. Br J Haematol. 2013 Dec;163(5):666-73.

43. Potze W, Arshad F, Adelmeijer J, Blokzijl H, van den Berg AP, Meijers $\mathrm{JC}$, et al. Differential in vitro inhibition of thrombin generation by anticoagulant drugs in plasma from patients with cirrhosis. PLoS One. 2014 Feb 4;9(2):e88390.

44. Shatzel J, Dulai PS, Harbin D, Cheung H, Reid TN, Kim J. Safety and efficacy of pharmacological thromboprophylaxis for hospitalized patients with cirrhosis: a single-center retrospective cohort study. J Thromb Haemost. 2015 Jul;13(7):1245-53.

45. Egan $\mathrm{G}$, Ensom MH. Measuring anti-factor xa activity to monitor lowmolecular-weight heparin in obesity: a critical review. Can J Hosp Pharm. 2015 Jan-Feb;68(1):33-47.

46. Lai S, Coppola B. Use of enoxaparin in end-stage renal disease. Kidney Int. 2013 Sep;84(3):433-6.

47. Bechmann LP, Sichau M, Wichert M, Gerken G, Kröger K, Hilgard P. Low-molecular-weight heparin in patients with advanced cirrhosis. Liver Int. 2011 Jan;31(1):75-82.

48. Senzolo M, Rodriguez-Castro KI, Rossetto V, Radu C, Gavasso S, Carraro $\mathrm{P}$, et al. Increased anticoagulant response to low-molecularweight heparin in plasma from patients with advanced cirrhosis. J Thromb Haemost. 2012 Sep:10(9):1823-9.

49. Chowdary P, Adamidou D, Riddell A, Aghighi S, Griffioen A, Priest P, et al. Thrombin generation assay identifies individual variability in responses to low molecular weight heparin in pregnancy: implications for anticoagulant monitoring. Br J Haematol. 2015 Mar;168(5):71927. doi: 10.1111/bjh.13193. Epub 2014 Oct 29.

50. Samama MM, Gerotziafas GT. Comparative pharmacokinetics of LMWHs. Semin Thromb Hemost. 2000;26 Suppl 1:31-8.

51. Atiq F, van den Bemt PM, Leebeek FW, van Gelder T, Versmissen J. A systematic review on the accumulation of prophylactic dosages of low-molecular-weight heparins (LMWHs) in patients with renal insufficiency. Eur J Clin Pharmacol. 2015 Aug;71(8):921-9.

52. Salem JE, Sabouret P, Funck-Brentano C, Hulot JS. Pharmacology and mechanisms of action of new oral anticoagulants. Fundam Clin Pharmacol. 2015 Feb;29(1):10-20.

53. Pollack CV Jr, Reilly PA, Eikelboom J, Glund S, Verhamme P, Bernstein RA, et al. Idarucizumab for Dabigatran Reversal. N Engl J Med. 2015 Aug 6;373(6):511-20.

54. Eikelboom JW, Weitz Jl. New anticoagulants. Circulation. 2010 Apr 6;121(13):1523-32.

55. Bauer KA. Recent progress in anticoagulant therapy: oral direct inhibitors of thrombin and factor Xa. J Thromb Haemost. 2011 Jul;9 Suppl 1:12-9.

56. Gehrie E, Tormey C. Novel oral anticoagulants: efficacy, laboratory measurement, and approaches to emergent reversal. Arch Pathol Lab Med. 2015 May;139(5):687-92.

57. van Ryn J, Stangier J, Haertter S, Liesenfeld KH, Wienen W, Feuring $M$, et al. Dabigatran etexilate--a novel, reversible, oral direct thrombin inhibitor: interpretation of coagulation assays and reversal of anticoagulant activity. Thromb Haemost. 2010 Jun;103(6):1116-27.

58. Samama MM. Coagulation Assays in Patients with New Oral Anticoagulants (NOACs): Why? When? Drug Development Research. 2013;74(8):582-6.

59. Božic-Mijovski M, Malmström RE, Malovrh P, Antovic JP4, Vene N, Šinigoj $P$, et al. Diluted thrombin time reliably measures low to intermediate plasma dabigatran concentrations. Ann Clin Biochem. 2016 Jul;53(Pt 4):446-51. doi: 10.1177/0004563215599795. Epub 2015 Sep 21.

60. Amitrano L, Guardascione MA, Menchise A, Martino R, Scaglione M, Giovine S, et al. Safety and efficacy of anticoagulation therapy with low molecular weight heparin for portal vein thrombosis in patients with liver cirrhosis. J Clin Gastroenterol. 2010 Jul;44(6):448-51.

61. Cui SB, Shu RH, Yan SP, Wu H, Chen Y, Wang L, et al. Efficacy and safety of anticoagulation therapy with different doses of enoxaparin for portal vein thrombosis in cirrhotic patients with hepatitis B. Eur J Gastroenterol Hepatol. 2015 Aug;27(8):914-9.

62. Delgado MG, Seijo S, Yepes I, Achécar L, Catalina MV, García-Criado A, et al. Efficacy and safety of anticoagulation on patients with cirrhosis and portal vein thrombosis. Clin Gastroenterol Hepatol. 2012 Jul; 10(7):776-83

63. Couturaud F, Sanchez O, Pernod G, Mismetti P, Jego P, Duhamel E, et al. Six Months vs Extended Oral Anticoagulation After a First Episode of Pulmonary Embolism: The PADIS-PE Randomized Clinical Trial. JAMA. 2015 Jul 7;314(1):31-40.

64. Martinez M, Tandra A, Vuppalanchi R. Treatment of acute portal vein thrombosis by nontraditional anticoagulation. Hepatology. 2014 Jul;:60(1):425-6.

65. Intagliata NM, Maitland H, Northup PG, Caldwell SH. Treating thrombosis in cirrhosis patients with new oral agents: ready or not? Hepatology. 2015 Feb;61(2):738-9.

66. Kubitza D, Roth A, Becka M, Alatrach A, Halabi A, Hinrichsen $\mathrm{H}$, et al. Effect of hepatic impairment on the pharmacokinetics and pharmacodynamics of a single dose of rivaroxaban, an oral, direct Factor Xa inhibitor. Br J Clin Pharmacol. 2013 Jul;76(1):89-98.

67. Simonetto DA, Wysokinski WE, Kamath PS. Use of nontraditional anticoagulants in portal vein thrombosis: a note of caution. Hepatology. 2015 Jun;61(6):2119.

68. Senzolo M. Liver: PVT in cirrhosis, not always an innocent bystander. Nat Rev Gastroenterol Hepatol. 2015 Jan;12(1):11-3.

69. Zocco MA, Di Stasio E, De Cristofaro R, Novi M, Ainora ME, Ponziani $F$, et al. Thrombotic risk factors in patients with liver cirrhosis: correlation with MELD scoring system and portal vein thrombosis development. J Hepatol. 2009 Oct;51(4):682-9.

70. Mancuso A. An update on the management of Budd-Chiari syndrome: the issues of timing and choice of treatment. Eur $\mathrm{J}$ Gastroenterol Hepatol. 2015 Mar;27(3):200-3.

71. Menon KV, Shah V, Kamath PS. The Budd-Chiari syndrome. N Engl J Med. 2004 Feb 5;350(6):578-85.

72. Sun J, Zhang Q, Xu H, Huang Q, Shen B, Zu M, et al. Clinical outcomes of warfarin anticoagulation after balloon dilation alone for the treatment of Budd-Chiari syndrome complicated by old inferior vena cava thrombosis. Ann Vasc Surg. 2014 Nov;28(8):1862-8. 
73. Chinnakotla S, Klintmalm GB, Kim P, Tomiyama K, Klintmalm E, Davis GL, et al. Long-term follow-up of liver transplantation for Budd-Chiari syndrome with antithrombotic therapy based on the etiology. Transplantation. 2011 Aug 15;92(3):341-5.

74. Gómez Cuervo C1, Bisbal Pardo 0, Pérez-Jacoiste Asín MA. Efficacy and safety of the use of heparin as thromboprophylaxis in patients with liver cirrhosis: a systematic review and meta-analysis. Thromb Res. 2013 0ct;132(4):414-9.

75. Barclay SM1, Jeffres MN, Nguyen K, Nguyen T. Evaluation of pharmacologic prophylaxis for venous thromboembolism in patients with chronic liver disease. Pharmacotherapy. 2013 Apr;33(4):375-82.

76. Cui J, Wu B, Liu C, Li Z. A systematic review and adjusted indirect comparison of oral anticoagulants. Orthopedics. 2014 Nov;37(11): 763-71.

77. Bauersachs RM. Use of anticoagulants in elderly patients. Thromb Res. 2012 Feb;129(2):107-15.

78. Abdel-Salam OM, Baiuomy AR, Ameen A, Hassan NS. A study of unfractionated and low molecular weight heparins in a model of cholestatic liver injury in the rat. Pharmacol Res. 2005 Jan;51(1): 59-67.

79. Dittmeier M, Kraft P, Schuhmann MK, Fluri F, Kleinschnitz C. Pretreatment with rivaroxaban attenuates stroke severity in rats by a dual antithrombotic and anti-inflammatory mechanism. Thromb Haemost. 2016 Apr;115(4):835-43.

80. Yang ZJ, Sheth SH, Smith CH, Schmotzer AR, Lippello AL, Al-Khafaj $A$, et al. Plasma from chronic liver disease subjects exhibit differentia ability to generate thrombin. Blood Coagul Fibrinolysis. 2015 Oct; 26(7):844-7.

81. Bates SM, Weitz JI. Coagulation assays. Circulation. 2005 Jul 26 112(4):e53-60.

82. Tripodi A, Chantarangkul V, Primignani M, Fabris F, Dell'Era A, Sei
C, et al. The international normalized ratio calibrated for cirrhosis (INR(liver)) normalizes prothrombin time results for model for end-stage liver disease calculation. Hepatology. 2007 Aug;46(2): 520-7.

83. Werner KT, Sando S, Carey EJ, Vargas HE, Byrne TJ, Douglas DD, et al. Portal vein thrombosis in patients with end stage liver disease awaiting liver transplantation: outcome of anticoagulation. Dig Dis Sci. 2013 Jun;58(6):1776-80.

84. Cai M, Zhu K, Huang W, Meng X, He K, Zhou B, et al. Portal vein thrombosis after partial splenic embolization in liver cirrhosis: efficacy of anticoagulation and long-term follow-up. Journal of vascular and interventional radiology. J Vasc Interv Radiol. 2013 Dec;24(12):180816.

85. Lai W, Lu SC, Li GY, Li CY, Wu JS, Guo QL, et al. Anticoagulation therapy prevents portal-splenic vein thrombosis after splenectomy with gastroesophageal devascularization. World J Gastroenterol. 2012 Jul 14;18(26):3443-50.

86. Widén A, Rolando N, Manousou P, Rolles K, Davidson B, Sharma D, et al. Anticoagulation after liver transplantation: a retrospective audit and case-control study. Blood Coagul Fibrinolysis. 2009 Dec;20(8): 615-8.

87. Francoz C, Belghiti J, Vilgrain V, Sommacale D, Paradis V, Condat B, et al. Splanchnic vein thrombosis in candidates for liver transplantation: usefulness of screening and anticoagulation. Gut. 2005 May:54(5): 691-7.

88. Lee SJ, Uhm JS, Kim JY, Pak HN, Lee MH, Joung B. The safety and efficacy of vitamin $\mathrm{K}$ antagonist in patients with atrial fibrillation and liver cirrhosis. Int J Cardiol. 2015 Feb 1;180:185-91.

89. Efird LM, Mishkin DS, Berlowitz DR, Ash AS, Hylek EM, Ozonoff A, et al. Stratifying the risks of oral anticoagulation in patients with liver disease. Circ Cardiovasc Qual Outcomes. 2014 May;7(3):461-7. 